\title{
Sensation Seeking and problematic use of technology among youth
}

\author{
Annalakshmi, N. ${ }^{1}$, Thasleema, N. ${ }^{2}$, Pooja Sri, S. ${ }^{3}$ \\ ${ }^{1,2,3}$ Department of Psychology, Bharathiar University, Coimbatore. \\ Corresponding author: Annalakshmi N. \\ Email - annalakshmi.narayanan@gmail.com
}

\begin{abstract}
Background: Technology is one platform that offers young people the excitement they seek. It is essential to examine if problematic use of technology is associated with personality factors, particularly sensation seeking tendencies, among youth. The present study examined the relationship between the four components of sensation seeking, namely, thrill and adventure seeking, disinhibition, experience-seeking, and boredom susceptibility, and problematic use of technology among youth.

Methodology: The study used a convenient sample of 200 young adults in the age group 18 to 25 years of age. The participants completed measures of sensation seeking and problematic use of technology in this study. The data were analyzed using one-way ANOVA and multiple regression. Males were higher on boredom susceptibility, disinhibition, experience seeking, and problematic internet use compared to females. Results: There was a significant difference between individuals from different locations on boredom susceptibility and disinhibition. Boredom susceptibility positively predicted problematic mobile use. Being a female negatively predicted problematic internet use. Thrill and adventure seeking negatively predicted problematic mobile use as well as problematic internet use. Problematic internet use was positively correlated with problematic mobile use.

Conclusions: The findings have implications for identifying young people who are vulnerable to problematic use of technology and design preventive interventions that would help them identify alternative and healthy ways of seeking sensations.
\end{abstract}

Key words: sensation seeking, youth, technology, internet use.

(Paper received $-24^{\text {th }}$ May 2020, Peer review completed $-30^{\text {th }}$ June 2020, Accepted $-4^{\text {th }}$ July 2020)

\section{INTRODUCTION}

Technology has become an indispensable part of everyone's lives in today's world. It has several positive impacts and downsides too. As per statistics by Internet Live Stats [1], an independent agency that surveys internet usage in the world, in January 2016, 34.8\% of Indians were active users of the internet. With yearly user growth of around $15-20 \%$, India ranked $2^{\text {nd }}$ on the total number of users globally, and shares $13.5 \%$ of world Internet use [1]. Imprudent use of technology has an adverse effect on society as a whole. A survey conducted by common sense media reported by Wallace [2] found that nearly $66 \%$ of parents reported that their teenage children spend excessive time on mobile phones. Nearly half of the teens feel that they are addicted to their mobile devices, while $72 \%$ feel the need to respond to texts, social networking messages, and other notifications immediately. According to reports by Pew Research Center (2019) [3], Indian men (34\%) are much more likely than women (15\%) to own smartphones. Pearson and Hussain [4] report that higher levels of narcissism and neuroticism were linked to smartphone addiction, and state that smartphones could encourage narcissism even in non-narcissistic users. Thus, there is adequate evidence that smartphones are psychologically addictive for children, encouraging narcissistic behavior, and should come with health warnings.

The term problematic internet use was coined by Goldberg [5]. Though there is no standardized definition for this term, problematic internet usage can be defined as a maladaptive preoccupation with Internet use, 
experienced as irresistible, for periods of time longer than intended [6]. Problematic internet usage is classified as either specific or generalized. The specific problematic internet usage denotes a particular context that exists independently from the internet, such as gambling and video games. On the other hand, generalized problematic internet usage refers to a specific internet context, including a chat room, email, and social networks such as Facebook and Twitter [7]. Problematic mobile use is an individual's inability to control their use of mobile phones, leading to negative consequences in their daily lives.

Internet usage is not yet recognized as a diagnosable disorder. However, several studies claim that excessive internet usage results in serious health consequences. DSM V recognizes Internet gaming disorder, a type of Internet addiction disorder, as a condition that requires more research to be considered as a disorder. Addiction occurs when an individuals' psychological state, including mental and emotional states, their scholastic, occupational and social interactions get impaired by overuse of the internet [8]. The signs and symptoms of addiction include the usage of internet longer than intended, preoccupation with the internet, withdrawal symptoms when unable to use the internet, unsuccessful attempts to stop or reduce internet use, craving, loss of interest in hobbies or activities other than the internet, excessive internet use despite the knowledge of related problems, use of the internet to escape or relieve a negative mood and lying about internet use [9]. Empirical studies identified increased rates of problematic internet users worldwide, which have serious negative consequences. The diagnostic criteria for internet addiction are not widely accepted. Researchers summated the symptoms of a substance use disorder, gambling disorder, and internet gaming disorder from DSM V to examine problematic internet use disorder.

Excessive internet use in adults has been associated with failed marriages, unemployment, neglected children, and sleep deprivation [10]. Problematic Internet use also results in social withdrawal, victimization, emotional instability, aggressiveness, anxiety, depression, substance abuse, and suicidal behavior [11]. Individuals have lower brain gray matter density in the left anterior cingulated cortex, left posterior cingulated cortex, left insula, and in left lingual gyrus, which are linked with internet addiction [12].

The reasons for the development of problematic use of technology can be many. The opportunity to access technology is one of the prime factors. Increased access to the internet at younger ages, increase in need to have the devices connected all the time, using them for work, downloading music and chatting, and great importance attributed to the social network may lead to the development of problematic use of technology [13]. The vulnerability of college students to internet addiction may be attributed to factors like continuous availability of internet, using the internet less for course work or assignments, making new friendships online, and getting into a relationship online [14]. The lack of awareness among parents needed for identifying technology abuse is another cause for addiction and may result in school failure, isolation, and aggressiveness. Another study reported that internet addiction was found to be associated with negative academic consequences such as missed classes, lower grades, and even academic dismissal [15]. Individuals who have a tendency to take risks and to be adventurous find technology an exciting medium to connect and communicate with others and to discover the unknown. Since when using the internet, people can be incognito with their identity concealed, they can protect themselves from the negative consequences of any inappropriate behavior they exhibit online. Problematic internet use is associated with retrieving sexual information, socialization, entertainment, and games [16].

Boredom is one of the factors leading to internet addiction among adolescents. They also face pressure to form social relationships, which forces them to use the internet [17]. Adolescents with less parental control are more likely to get addicted to the internet [18]. Self-esteem was found to a significant predictor of internet addiction [19]. This was supported by Griffith's [20] study that the participants' use of the internet is highly associated their perception of it as a coping style and a way of compensating some deficiencies, such as low self-esteem, and it makes users feel better, as it allows them to assume a different personality and social identity. The main cause of using the computer and the internet was reported to be chatting and games [21]. Students with parents who demonstrated neglectful parenting styles, where parents are low in responsiveness as well as control, were found to be more socially reticent than students with parents demonstrating other parenting styles [22]. It also found that male students with authoritative, permissive, and neglectful parenting styles are more socially reticent than authoritarian parenting styles. The proper socialization of the young is an important aspect in the present era [22]. Poor social skills can result in increased vulnerability that can 
manifest in efforts to avoid real-life social interactions and engage more in the virtual world. This also could lead to addiction to the internet and technology.

Adolescents who perceive their parents as knowing about their whereabouts and monitoring their activities are less likely to engage in risky behaviors. Perceived parental monitoring acts as a buffer for adolescent risky behavior in this study; the most powerful proximal influence on involvement in risky behaviors in adolescence is perceived peer activities. Increased youth sensation seeking is associated with lower levels of parental monitoring, which in turn is associated with increased risk involvement. Decreased parental monitoring is also associated with reporting more friends who engage in various types of risky behaviors [23]. Individuals who feel lonely because of their lack of good social skills try to overcome their problems through online social interactions [24]. The higher the level of shyness, the greater is the likelihood that one would be addicted to the Internet [25-26]. Boredom, the pressure to form social relationships, low selfesteem, peer influence, parenting style, and parental supervision are the various factors leading to problematic technology use among adolescents.

Personality plays a major role in the problematic usage of technology. It is found that adolescents who are high in experience seeking use technology in a problematic manner. Furthermore, individuals who are high on neuroticism, psychoticism, and anxiety, and the ones who respond to stressors poorly also use technology in a problematic way [27]. Another predictor of problematic internet use is low self-directedness [28]. Clinical symptoms, including depression, cognitive distortion, and substance usage, also pave the way to problematic internet use. A study on personality traits and internet addiction reports that excessive use of the internet was strongly associated with high levels of neuroticism [29] and psychoticism [30] among adolescents revealing on one hand anxieties, sensitivity to threat and a poor response to stressors, and on the other hand, impulsivity and sensation-seeking traits. Moreover, adolescents with dysfunctional and dysregulated internet use seem to be characterized by low resourcefulness, high emotional instability, and social introversion. Problematic involvement in online activities is associated with emotional instability, impulsivity, and aggressiveness, which facilitate the expression of dysregulated, unintegrated, and even violent reactions to stressful situations. Low self-discipline is found to be a predictor variable in all subdimensions of problematic internet use like negative effects of the internet, social benefits or social conformity and excessive usage of the internet [31].

Experience seeking is one of the factors that has an influence on problematic Internet use. High school students who are ambitiously seeking new experiences spend a large amount of their time on the internet because the possibility of its new experiences highly appeals to them. According to the cognitive-behavioral approach model [32], the key factor in the continuation of internet activities is the reinforcement the individual finds in the activity. An important factor that is associated with increased vulnerability to problematic internet usage is gender. Men are at greater risk of social impairment due to problematic internet use. Baloglu, Kozan, and Kesici [33] found that men reported having more difficulties in terms of running away from personal problems and using the internet excessively compared to women. Further, men also reported experiencing more interpersonal problems due to excessive internet use compared to women. Also, there are associations between social anxiety and problematic internet use, and the association is stronger for men than women [33].

Researchers reported that boys differed from girls on why they used the internet: Boys spent more time on the internet than girls for massive multiplayer online role-playing games, online games and adult sites, while girls made intense use of social networks [34]. Another study [35] reported that boys' use of the internet for social media, YouTube, blogs, massively multiplayer online games (MMO) and online gaming while girls' use of the internet for social media, YouTube, blogs, downloading films and music contributed to internet addiction test (IAT) total score. Playing MMO and reading blogs are more likely to be linked to problematic internet use in men, but the use of social media and blogs increases the risk for problematic internet use in women. Males are reported to have 50 percent increased odds than females for internet addiction with drinking behavior, family dissatisfaction, and stress-related factors increasing the risk [36].

Among personality traits, sensation seeking could be seen as a relevant factor linked to problematic technology use among adolescents. According to Zuckerman [37], sensation seeking is the search for a wide range of new, complex, vivid sensations and experiences, and opportunities for taking several risks that could be physical, social, and financial. With sensation seekers' attraction for unfamiliar things, they are often 
found to engage in extreme fun or sports activity, risky ventures, new sexual experiences, and challenge existing beliefs, besides enjoying journey and new foods. Sensation seekers tend to avoid activities that are repetitive and predictive in nature and seek unusual activities such as sky diving, mountaineering, scuba diving, gambling, or even experiment with drugs.

People who scored high on sensation-seeking are more likely to misuse drugs, engage in risky sexual activities, and suffer accidental injuries than people with low sensation seeking [38]. Sensation seeking is not only reflecting a potential for taking risks but also reflects the quality of seeking intensity and novelty in seeking experience, which may be expressed in multiple areas of a person's life [39]. Sensation seeking has been invoked to explain a wide variety of behaviors and was found to be positively correlated with risk behavior, dislike of structured and formal situations, adventure travel, tendency to avoid repetition, liking of intense experiences, proneness to boredom under restrained and repetitive situations and a tendency toward disinhibition [40]. Sensation seekers tend to smoke, believe less in conventional religion [41] and volunteer more often for unusual experiences and activities such as sensory deprivation and hypnosis [42], drug research, alpha control, meditation training and gambling classes [43]. Those with high sensation seeking are likely to choose jobs that require high levels of change, some risks, and tractability [43].

Sensation seekers' higher need for stimulation results in taking risks and seeking thrills, making them vulnerable to unhealthy behaviors in some contexts. Sensation seeking could be one of the many personality traits that can influence problematic technology use. The present study aimed at examining the relationship between sensation seeking on the one hand and problematic mobile use and problematic internet use on the other hand. Further, the gender differences in sensation seeking, problematic use of mobile phones, and problematic use of internet are also examined in this study. We also examined the differences between samples drawn from different geographical locations on problematic use of mobile phones and problematic use of internet.

\section{METHODOLOGY}

\section{Study Participants}

The convenient sample selected for the study consisted of 200 college students in the age group of 18 to 25 years $(\mathrm{M}=9.37, \mathrm{SD}=.67)$ from two southern states of India, i.e., Kerala and Tamil Nadu. There were 100 students (Males $=46$, Females=54) from Kerala and 100 students (Males=49, Females=51) from Tamil Nadu in the sample. Out of 200 participants, around $65 \%$ were from rural areas. About $76.5 \%$ belonged to OC community, $7 \%$ belonged to MBC, and $16.5 \%$ belonged to SC/ST community. About $87 \%$ of the participants lived in houses owned by them while the others lived in rented houses.

\section{Measures used -}

1. Sensation Seeking Scale (SSS): The Sensation-Seeking Scale (Form V) consisted of 40 forcedchoice items. Originally developed as an individual difference measure to predict differential response to sensory deprivation, the sensation-seeking scale evolved into a multidimensional measure consisting of four interrelated subscales [37]. The subscales, each comprising of ten forcedchoice items, include boredom susceptibility, disinhibition, experience seeking, thrill and adventure seeking. Boredom susceptibility is an aversion to repetition, routine and dull people; disinhibition is the desire for social and sexual disinhibition; experience seeking is the desire for experience through the mind and senses, travel and non-conforming lifestyles, and thrill and adventure-seeking is the desire to engage in sports or activities involving speed and danger. The respondents were asked to choose between two response options, one indicative of the presence of the tendency to seek sensations, and the other indicative of the absence of such a tendency. The original number of items on this scale was 40 , and the reliability was found to be $.23, .47, .22$ and .62 for boredom susceptibility, disinhibition, experience seeking, and thrill and adventure-seeking respectively. The overall reliability of the scale was .68 . An item analysis was carried on the items of the original 40 items since the reliability was not adequate. Since items 2, 7, 31, 8 (reversed) and 39 (reversed) from boredom susceptibility, item 33 (reversed) from disinhibition, items 4, 26, 37, 14 (reversed) and 22 from experience seeking and item 38 (reversed) from thrill and adventure seeking had poor 
reliability they were removed from the original 40 -item scale. After item analysis, 12 items were removed, and the final number of items on the scale was 28 . The final number of items in the subscale boredom susceptibility, disinhibition, experience seeking, thrill and adventure-seeking are $5,9,5$, and 9, respectively. The alphas for the boredom susceptibility, disinhibition, experience seeking and thrill, and adventure seeking on the present sample were $.36, .49, .37$, and .64 , respectively. The reliability coefficient of the final scale on the present sample was found to be 69 .

2. Problematic and Risky Internet Use Screening Scale (PRIUSS): The PRIUSS scale was used to measure the problematic internet use of youths and adolescents [44]. The scale consists of 18 items, and the participants are asked to respond to these items based on their experience and feelings over the past six years. The scale consists of three subscales, namely social impairment, emotional impairment, and risky/impulsive internet use. Social impairment (items 1-6) assesses the impact of internet use on both offline and online social interactions. Emotional impairment (items 7-11) measures the degree of emotional attachment to internet use. Risky/impulsive internet use (items 12-18) assesses salient problematic behaviors regarding internet use. A sample item from this scale is 'Do you neglect your responsibilities because of internet.' The respondents are first asked whether they have experienced this over the past six years. If yes, then they are asked to mark the intensity of the experience or feeling on a five-point scale ( $0=$ Never, $1=$ Rarely, $2=$ Sometimes, $3=$ Often, $4=$ Very Often). The scores across the items under each subscale were added to obtain the subscale score, and the final score of problematic internet usage was obtained by summing up the subscale scores The reliability of the subscales social impairment, emotional impairment, and risky/impulsive internet use on the present sample were found to be $.62, .73$ and .75 respectively. The overall reliability of the scale was found to be .85 .

3. Problematic Use of Mobile Phones (PUMP): The PUMP consists of 20 items that purport to measure the respondents' phone usage and the consequences of excessive internet use [45]. The scale consists of ten subscales with two items each. The subscales are tolerance, withdrawal, a longer time than intended, a great deal of time spend, craving, activities given up or reduced, use despite physical and psychological problems, failure to fulfill role obligations, use in physically hazardous situations and use despite social or interpersonal problems. The respondents are first asked to read each item on the scale and decide how much they agree or disagree with each statement. A sample item on the scale is 'When I stopped using my mobile phone, I get moody and irritable.' The respondent is then asked to rate their agreement or disagreement with each statement using a fivepoint rating scale ( $1=$ Strongly Disagree, $2=$ Disagree, $3=$ Neutral, $4=$ Agree, $5=$ Strongly Agree). The scores of the respondents on each item under each subscale were summed up to obtain the subscale scores. The final score of the respondent on problematic mobile usage was obtained by summing up the subscale scores. For analysis in the present study, only the total score on the scale was used. The reliability of the overall scale was found to be .88 .

\section{Procedure}

The data of the present study was collected from 200 students studying in colleges located in two southern states, Kerala and Tamil Nadu. Institutional approval for collecting data was obtained from authorities of the colleges in Kerala and Tamil Nadu, and a convenient date and time were set for data collection. The written informed consent was obtained from the participants. The questionnaire was group-administered with not more than 30 students in a group in their classrooms during college working hours.

\section{RESULTS}

Students of different genders were compared on sensation seeking, problematic internet use and problematic mobile phone use using a one-way analysis of variance. The descriptive statistics of the variables used in the study are presented in the table below (Table 1).

A one-way analysis of variance carried out to examine the gender difference on the present study variables revealed that there was a significant effect for gender on boredom susceptibility, $F(1,198)=4.31, p=.039$, with men $(M=1.65, S D=1.18)$ having higher scores than females $(M=1.31, S D=1.12)$. Also, there was a 
significant effect for gender on disinhibition, $\mathrm{F}(1,197)=32.83, \quad \mathrm{p}=.001$ with men $(\mathrm{M}=3.13, \mathrm{SD}=1.63)$ having higher scores than females $(\mathrm{M}=1.89, \mathrm{SD}=1.43)$. There was significant difference between the genders on experience seeking, $\mathrm{F}(1,198)=6.19, \mathrm{p}=.014$, with men $(\mathrm{M}=2.00, \mathrm{SD}=1.23)$ having higher scores than females $(M=1.59, \mathrm{SD}=1.10)$. There was a significant effect for gender on problematic and risky internet use, $\mathrm{F}(1,193)=8.58, \mathrm{p}=.004$, with men $(\mathrm{M}=29.77, \mathrm{SD}=12.00)$ having high scores than females $(\mathrm{M}=24.81$, $\mathrm{SD}=11.59)$.

Table 1 - Descriptive variables used in the study

\begin{tabular}{|l|c|c|c|}
\hline \multicolumn{1}{|c|}{ Variable } & Mean & SD & SE \\
\hline Boredom susceptibility & 1.48 & 1.16 & 0.08 \\
\hline Disinhibition & 2.47 & 1.64 & 0.12 \\
\hline Experience seeking & 1.79 & 1.18 & 0.08 \\
\hline Thrill and adventure seeking & 5.91 & 1.99 & 0.14 \\
\hline Problematic and risky internet use & 27.10 & 12.01 & 0.86 \\
\hline Problematic use of mobile phone & 54.70 & 13.47 & 0.96 \\
\hline
\end{tabular}

Table 2 - Summary of ANOVA comparing males $(\mathrm{N}=95)$ and females $(\mathrm{N}=105)$ on sensation seeking, problematic internet use and problematic mobile phone use

\begin{tabular}{|c|c|c|c|c|c|}
\hline Variables & Gender & $\mathbf{M}$ & SD & $\mathbf{F}$ & $p$ \\
\hline \multirow[t]{2}{*}{ Boredom susceptibility } & Males & 1.65 & 1.18 & \multirow[t]{2}{*}{4.31} & \multirow[t]{2}{*}{.039} \\
\hline & Females & 1.31 & 1.12 & & \\
\hline \multirow[t]{2}{*}{ Disinhibition } & Males & 3.13 & 1.63 & \multirow[t]{2}{*}{32.83} & \multirow[t]{2}{*}{.001} \\
\hline & Females & 1.89 & 1.43 & & \\
\hline \multirow[t]{2}{*}{ Experience seeking } & Males & 2.00 & 1.23 & \multirow[t]{2}{*}{6.19} & \multirow[t]{2}{*}{.014} \\
\hline & Females & 1.59 & 1.10 & & \\
\hline \multirow[t]{2}{*}{ Thrill and adventure seeking } & Males & 5.93 & 2.09 & \multirow[t]{2}{*}{0.02} & \multirow[t]{2}{*}{.886} \\
\hline & Females & 5.89 & 1.90 & & \\
\hline \multirow[t]{2}{*}{ Problematic and Risky Internet Use } & Males & 29.77 & 12.00 & \multirow[t]{2}{*}{8.58} & \multirow[t]{2}{*}{.004} \\
\hline & Females & 24.81 & 11.59 & & \\
\hline \multirow[t]{2}{*}{ Problematic Use of Mobile Phone } & Males & 55.19 & 12.13 & \multirow[t]{2}{*}{0.24} & \multirow[t]{2}{*}{.626} \\
\hline & Females & 54.25 & 14.64 & & \\
\hline
\end{tabular}

Table 3 - Summary of ANOVA comparing participants from Tamil Nadu ( $N=99)$ and Kerala $(\mathrm{N}=100)$ on sensation seeking, problematic internet use and problematic mobile phone use

\begin{tabular}{|l|l|c|c|c|c|}
\hline \multicolumn{1}{|c|}{ Variable } & \multicolumn{1}{|c|}{ Group } & Mean & SD & F & \multicolumn{1}{c|}{$\boldsymbol{p}$} \\
\hline Boredom susceptibility & Tamil Nadu & 1.06 & 0.98 & 29.22 & .001 \\
\cline { 2 - 5 } & Kerala & 1.89 & 1.18 & & \\
\hline \multirow{2}{*}{ Disinhibition } & Tamil Nadu & 2.33 & 1.54 & 1.51 & .221 \\
\cline { 2 - 5 } & Kerala & 2.62 & 1.74 & & \\
\hline \multirow{2}{*}{ Experience seeking } & Tamil Nadu & 1.67 & 1.17 & 1.92 & .168 \\
\cline { 2 - 5 } & Kerala & 1.90 & 1.18 & & \\
\hline Thrill and adventure seeking & Tamil Nadu & 5.54 & 1.95 & \multirow{2}{*}{6.94} & .009 \\
\cline { 2 - 4 } & Kerala & 6.27 & 1.97 & & \\
\hline \multirow{2}{*}{ Problematic and Risky Internet Use } & Tamil Nadu & 25.67 & 12.69 & \multirow{2}{*}{2.93} & .089 \\
\cline { 2 - 4 } & Kerala & 28.60 & 11.12 & & \\
\hline \multirow{2}{*}{ Problematic Use of Mobile Phone } & Tamil Nadu & 53.03 & 13.41 & \multirow{2}{*}{3.15} & .078 \\
\cline { 2 - 4 } & Kerala & 56.41 & 13.37 & & \\
\hline
\end{tabular}


There was no significant difference between genders on thrill and adventure seeking $[\mathrm{F}(1,198)=0.02, \mathrm{p}=$ $.886]$ and problematic use of the mobile phone $[\mathrm{F}(1,196)=.24, \mathrm{p}=.626]$ as may be seen in Table 2 .

There is significant difference between participants from different states on boredom susceptibility, $\mathrm{F}(1,198)$ $=29.22, \mathrm{p}=.001$, with participants from Kerala $(\mathrm{M}=1.89, \mathrm{SD}=1.18)$ having higher scores than those from Tamil Nadu (M=1.06, $\mathrm{SD}=0.98$. Also, there is a significant difference between participants from different states on thrill and adventure seeking, $F(1,198)=6.94, p=.009$, with participants from Kerala $(M=6.27$. $\mathrm{SD}=1.97)$ having higher scores than participants from Tamil $\mathrm{Nadu}(\mathrm{M}=5.54, \mathrm{SD}=1.95)$.

There was no significant difference between participants from different states on disinhibition $[\mathrm{F}(1,197)$ $=1.51, \mathrm{p}=.221]$, experience seeking $[\mathrm{F}(1,198)=1.92, \mathrm{p}=.168]$, problematic and risky internet use $[\mathrm{F}(1$, $193)=2.93, p=.089]$, and problematic use of mobile phone $[F(1,196)=3.15, p=.078]$.

Table 4 - Components of sensation seeking predicting problematic mobile use

\begin{tabular}{|l|c|c|c|c|c|}
\hline \multirow{2}{*}{ Variables } & \multicolumn{2}{|c|}{ Unstd. Coeff. } & Std. Coeff. & \multirow{2}{*}{ Sig. } & \multirow{2}{*}{ Std. Error } \\
\cline { 2 - 4 } & $\boldsymbol{B}$ & Beta & & \\
\hline Gender & 1.37 & 2.01 & 0.05 & 0.68 & .495 \\
\hline Boredom susceptibility & 2.16 & 0.88 & 0.19 & 2.46 & .015 \\
\hline Disinhibition & 1.28 & 0.69 & 0.16 & 1.86 & .064 \\
\hline Experience seeking & 0.26 & 0.91 & 0.02 & 0.28 & .779 \\
\hline Thrill and adventure seeking & -1.03 & 0.48 & -0.15 & -2.14 & .034 \\
\hline
\end{tabular}

$\left[\mathrm{R}^{2}=.086\right.$, Adjusted $\left.\mathrm{R}^{2} .062, \mathrm{~F}(5,191)=3.58, \mathrm{p}<.004\right]$

Multiple regression was carried out to examine if different components of sensation seeking predict problematic mobile use. Boredom susceptibility and thrill and adventure seeking $\left[R^{2}=.086\right.$, Adjusted $R^{2}$ $.062, \mathrm{~F}(5,191)=3.58, \mathrm{p}<.004]$ significantly predict problematic mobile use. Boredom susceptibility $(\beta=0.19$, $\mathrm{p}<.015)$ positively predicts problematic mobile use, whereas, thrill and adventure seeking $(\beta=-0.15, p<.034)$ negatively predict problematic mobile use.

Table 5 - Components of sensation seeking predicting problematic internet use

\begin{tabular}{|l|c|c|c|c|c|}
\hline \multirow{2}{*}{ Variable } & \multicolumn{2}{|c|}{ Unstd. Coeff. } & Std. Coeff. & \multirow{2}{*}{ S } & \multirow{2}{*}{ Sig } \\
\cline { 2 - 6 } & $\boldsymbol{B}$ & Std. error & Beta & & \\
\hline Gender & -3.76 & 1.81 & -0.16 & -2.08 & .039 \\
\hline Boredom susceptibility & 1.06 & 0.78 & 0.10 & 1.37 & .172 \\
\hline Disinhibition & .56 & 0.61 & 0.08 & 0.91 & .364 \\
\hline Experience seeking & .40 & 0.81 & 0.04 & 0.49 & .625 \\
\hline Thrill and adventure seeking & -1.23 & 0.43 & -0.20 & -2.88 & .004 \\
\hline
\end{tabular}

$\left[\mathrm{R}^{2}=.098\right.$, Adjusted $\left.\mathrm{R}^{2}=.074, \mathrm{~F}(5,188)=4.10, \mathrm{p}<.001\right]$

Multiple regression analysis was carried out to find the predictors of problematic internet use. Gender and thrill and adventure seeking $\left[\mathrm{R}^{2}=.098\right.$, Adjusted $\left.\left.\mathrm{R}^{2}=.074, \mathrm{~F}(5,188)=4.10, \mathrm{p}<.001\right)\right]$ significantly predicted problematic internet use. Gender $(\beta=-0.16, p<.039)$, and thrill and adventure seeking $(\beta=-0.20, p<.004)$ emerged to be a negative predictor of problematic internet use. Thus, being females, and thrill and adventure seeking negatively predict problematic internet use.

The correlation between problematic mobile use and problematic internet use was also examined using the Pearson correlation. It was found that problematic internet use and problematic mobile use were significantly positively correlated, $\mathrm{r}=.51, \mathrm{p}<.001$. 


\section{DISCUSSION}

The present study examined the relationship between sensation seeking and the problematic use of technology among youth. One of the key findings of the study is that there exists gender difference with regard to certain components of sensation seeking: Males reported higher levels of boredom susceptibility, disinhibition, and experience seeking compared to females. Further, it was also found that males reported higher levels of problematic internet use compared to females. The study examined whether students from different states differed with regard to personality in terms of sensation seeking. It is interesting to note that students from Kerala were higher on boredom susceptibility, thrill and adventure seeking compared to those from Tamil Nadu. The present study also found that problematic mobile use was positively correlated with problematic internet use. Different components of sensation seeking predicted problematic mobile use. Boredom susceptibility positively predicted problematic mobile use. Thrill and adventure seeing negatively predicted both problematic mobile use and problematic internet use. The regression results showed that gender, i.e., being a female negatively predicted problematic internet use.

In the present study, gender differences with regard to sensations seeking as well as problematic technology use were found to be significant. Males are higher than females on boredom susceptibility, disinhibition, and experience seeking. This is in line with studies that report males having greater predisposition to engage in uninhibited social interaction and also show greater tendency to avoid repetitive activities than females, and that socially transmitted social norms and stereotypes promote sensation seeking in males [38]. This gender difference could be attributed to the differences in the socialization of children. Individuals constantly interact with others in their social group, and hence are constantly influenced by group norms, dynamics, and expectations. Parental involvement in offsprings support more risk aversive strategies in females than males [46]. Further, it is also reported that men score higher than women on sensation-seeking, and this difference could be genetically influenced and these predispositions also interact with information that is socially transmitted [38].

The findings of ANOVA and regression show that males were more vulnerable to problematic internet use compared to females. This is in line with other studies on problematic internet use. Males are more addicted to the internet [47], mainly for gambling, but also for gaming. Men are more likely to express interest in games, pornography, and gambling activities that have all been associated with problematic internet use [48]. A higher rate of problematic internet use is found among males compared to females, and it can be due to the difference in the availability of favorite activities, such as online games, for the two sexes [49]. The main cause of men using the computer and the internet was for chatting and games [21]. The gender difference is explained by the preference of men to use the internet for sexual satisfaction and for online gaming when compared with females. Males are more involved in online activities such as gaming, pornography, and gambling, and this can lead to problematic internet use [50-51]. Men are at a higher pressure than women to form social relations and to become members of social networks, to form intimate relationships and to develop themselves. This pressure results in a tendency of men to use the internet in order to succeed in their social relations [17]. Further, the vulnerability of college students to internet addiction may be attributed to continuous availability of the internet, using the internet less for coursework or assignments, making new friendships online, and getting into relationships online [14]. Individuals who feel lonely because of their lack of good social skills try to overcome their problems through online social interactions [24]. Other factors such as less parental supervision, use of the internet for entertainment, and more experience in using the internet are also recognized as causes of problematic use of the internet.

Boredom susceptibility positively predicted problematic mobile phone use in the present study. Persons who scored high on sensation seeking and leisure boredom are more likely to get addicted to mobile phones than those who were low on sensation seeing and leisure boredom. The most powerful predictors for feature use of the mobile phone were addictive symptoms. Individuals who use mobile phone features heavily for sending or receiving SMS, for entertainment, and for information, tended to be those who felt anxious and even lost without their mobile phones, experienced a sense of losing control, and often received complaints from family and friends. Those who scored high on sensation seeking were those who often enjoyed the entertainment functions of sending and receiving pictures, playing electronic games, and downloading ring tones on their mobile phones [52]. Impulsivity played a specific role in mobile phone use; urgency was found

Indian Journal of Mental Health 2020;7(3) 
to be the strongest predictor of problematic mobile use [53]. Though previous studies have reported that students found Facebook addictive, the actual amount of time one spends on social media may actually be suggesting habit formation rather than addictive properties [54]. Individuals who feel lonely because of their lack of good social skills try to overcome their problems through online social interactions [24]. Internet and mobile phone addicts may feel their social discomfort is alleviated when interacting with others online because of the greater anonymity that internet can offer, and continue to use the internet instead of meeting people offline [48]. People may become addicted to media use in their attempts to bolster their self-esteem [55]. Impulsiveness, i.e., inability to delay gratification is associated with addictive behaviors [56]. Individuals who are high on impulsiveness are pushed by need satisfaction without any inhibition [57]. This can also lead to problematic mobile phone use.

Students from Kerala are higher in boredom susceptibility, thrill and adventure seeking. Kish [58] proposed an interactionist view in the contributions of heredity and family environment to sensation seeking trait, suggesting that fearful, overprotective parents who are also likely to be low sensation seekers, may discourage certain kinds of exploration and risk-taking in their children, which other parents may encourage. Thus, these parents may influence the development of the trait in their children both by serving as a role model and by providing negative reinforcement of risk-taking and non-conformity. Parental supervision has an important role in the behavioral expression of sensation-seeking traits, and also in excessive drug use and alcohol and tobacco misuse [59]. Higher levels of sensation seeking and lower levels of parental monitoring are linked to an increased vulnerability to substance abuse [59]. One possible explanation for the differences seen in sensation seeking between the samples from the two states, Kerala and Tamil Nadu, could be the cultural differences between the states that are reflected in parenting styles and socialization process. Nevertheless, this needs to be examined further to be conclusive.

Thrill and adventure seeking traits negatively predicts both problematic mobile use and problematic internet use. Thrill and adventure seeking behaviors involve several risks and can even lead to serious injury or even death in extreme cases. Zuckerman's theory [60] states that people who undertake risky outdoor behavior are sensation seekers. They prefer exciting, outdoor activities that are stimulating than depending on their phones. They prefer natural environments as a source of stimulation [60]. For learning new skills, adventure behavior is an experiential method that requires the use of all senses and cognitive processes [61]. Internet dependents were reported to obtain significantly lower scores on thrill and adventure seeking, excitement seeking, and overall sensation-seeking than non-dependents [62]. People with stronger stimulation and those who display behavior that manifests a greater desire for sensations prefer outdoor activities than browsing the internet. Since the outside world offers more stimulation through adventure activities, trekking, mountain climbing, scuba diving, skydiving, and the like, thrill and adventure seekers do not prefer mobile phones or the internet.

There exists a positive correlation between problematic internet use and problematic mobile use. According to the Ericsson Mobility Report [63], India has the highest average usage of internet per smartphone, reaching 9.8 gigabytes $(\mathrm{GB})$ per month by the end of 2018. The rapid growth of the internet can be attributed to factors such as huge options of service providers, attractive data plans, high long-term evolution (LTE) subscriptions, and increasing video views among youth. As per Kantar ICUBE report [64], monthly active internet usage crosses 574 million people in India in 2019 and these active internet users browse internet through their mobile phone. The increased availability of bandwidth, cheap data plans, and increased awareness driven by government programs seem to have rapidly bridged the digital gap between urban and rural India. Students are steered toward more Internet use because of many factors such as different cheap offers of internet recharge by different telecom companies, blocks of unstructured time, newly experienced freedom from parental intervention, no monitoring of what they express online, peer pressure and gaining random instant popularity on social media platform [65].

Problematic use of the internet and mobile phones can be defined as an inability to regulate one's use of the internet and mobile phones, which eventually has an adverse impact on health, social and financial aspects of life [66]. The risk group for smartphone addiction was reported to spend more time on the smartphone, mobile messenger, and social networking sites (SNS) than the normal user group [67]. Technology and technological advances, together with improved availability and accessibility, may contribute to potentially addictive online activities such as gambling via the internet and/or using smartphones [68]. Also, 
problematic internet and mobile phone users can suffer mood modification, loss of control, relapse, craving, tolerance, withdrawal, and conflict, among others [69], just like any other addictive behavior.

The findings of the present study must be understood within the limitations of the study. One of the limitations of the present study is that it is cross-sectional in nature, so causal relationships between the variables studied cannot be established. The study used exclusively self-report measures. The use of multiple sources of data could have strengthened the validity of the findings. If the study used qualitative data in addition to the quantitative data, more valuable insights into the exact nature of the problematic mobile use and problematic internet use could have been achieved.

\section{CONCLUSIONS}

The findings of the present study suggest that sensation seeking can increase the vulnerability to problematic technology use. Mobile and internet usage can serve as a channel for adventure, entertainment, sexual information and socialization, besides providing an opportunity to explore new phenomena for sensation seekers who get bored easily with repetition, predictable experiences, and daily life issues. Sensation seeking behavior like boredom susceptibility and disinhibition may increase problematic technology use. However, enhancing thrill and adventure seeking tendencies and encouraging individuals to engage in sensation seeking behaviors outdoors may support a healthier alternative to problematic technology use. Providing awareness to young people on sensation seeking, and helping them to channelize their sensation seeking tendencies in a healthier manner may be a helpful preventive intervention for problematic mobile and internet use.

\section{REFERENCES}

1. Internet Live Stats. Internet Users by Country 2016. Retrived from https://www.internetlivestats.com/internet-users-by-country/

2. Wallace K. Half of teens think they're addicted to their smartphones. CNN, Turner Broadcasting. July 29, 2016.

3. Pew Research Center. Smartphone ownership is growing rapidly around the world, but not always equally. Feb $5^{\text {th }}$ 2019. Retrieved from https://www.pewresearch.org/global/2019/02/05/smartphone-ownership-isgrowing-rapidly-around-the-world-but-not-always-equally/

4. Pearson C, Hussain Z. Smartphone use, addiction, narcissism, and personality: A mixed-methods investigation. Int J Cyber Behav Psychol Learning, 2015;5(1):17-32.

5. Goldberg I. IAD, In Cinti M. E.(a cura di) Internet Addiction Disorder un fenomeno sociale in espansione pp.6-7; 1995. Available: http://www.iucf.indiana.edu/brown/hyplan/addict.html.

6. Shapira NA, Goldsmith TD, Keck PE Jr, Khosla UM, McElroy SL. Psychiatric features of individuals with problematic internet use. J Affect Disord 2000;57(1-3):267-72.

7. Davis RA. A cognitive-behavioural model of pathologicalInternet use. Comp Hum Behav 2001;17(2),:187-95.

8. Beard KW. Internet addiction: a review of current assessment techniques and potential assessment questions. Cyberpsychol Behav 2005;8(1):7-14.

9. Li W, O'Brien JE, Snyder SM, Howard MO. Characteristics of Internet Addiction/Pathological Internet Use in U.S. University Students: A Qualitative-Method Investigation. PLoS One 2015;10(2):e0117372.

10. Young KS. Internet addiction: the emergence of a new clinical disorder. Cyberpsychol Behav 1998;1:237-44.

11. Zsila Á, Orosz G, Király O, Urbán R, Ujhelyi A, Jármi É, Griffiths MD, Elekes Z, Demetrovics Z. Psychoactive substance use and problematic internet use as predictors of bullying and cyberbullying victimization. Int J Ment Health Addict 2018;16(2):466-79.

12. Zhou Y, Lin FC, Du YS, Qin LD, Zhao ZM, Xu JR, Lei H. Gray matter abnormalities in Internet addiction: A voxel-based morphometry study. Eur J Radiol 2011;79(1):92-5.

13. de la Fuente Anuncibay R. ICTs and Teenage Students. Problematic Usage or Dependence. Proc Soc Behav Sci 2017;1:230-6.

14. Krishnamurthy S, Chetlapalli S. Internet addiction: Prevalence and risk factors: A cross-sectional study among college students in Bengaluru, the Silicon Valley of India. Indian J Pub Health 2015;59(2):115-9.

15. Moreno MA. Problematic internet use among US youth. Arch Pediatr Adolesc Med 2011;165(9):797-805.

16. Kormas G, Critselis E, Janikian M, Kafetzis D, Tsitsika A. Risk factors and psychosocial characteristics of potential problematic and problematic internet use among adolescents: A cross-sectional study. BMC Pub Health 2011;11(1):595-602.

17. Frangos CC, Frangos CC, Sotiropoulos I. Problematic internet use among Geek university students: An ordinal logistic regression with risk factors of negative psychological beliefs, pornographic sites, and online games. Cyberpsychol Behav Soc Network 2011;14(1-2):51-8. 
18. Martins MV, Formiga A, Santos C, Sousa D, Resende C, Campos R, Nogueira N, Carvalho P, Ferreira S. Adolescent internet addiction-role of parental control and adolescent behaviours. Int J Pediatr Adolesc Med 2019;10(1):55-74.

19. Błachnio A, Przepiorka A, Senol-Durak E, Durak M, Sherstyuk L. The role of personality traits in Facebook and internet addictions: A study on Polish, Turkish, and Ukrainian samples. Comp Hum Behav 2017;68: 26975 .

20. Griffiths MD. Does Internet and "addiction" exist? Some case study evidence. Cyberpsychol Behav 2000;3: 211-8.

21. Shaheen HM, Farahat TM, Gaber HM. Problematic Internet Use among Medical School Students in Menoufia University Egypt. J Child. Adolesc Behav 2016;4:298.

22. Mumthas NS, Rajan S. Influence of parenting styles on social reticence among higher secondary school students. Guru J Behav Soc Sci 2015;3(4):478-83.

23. Wang B, Deveaux L, Lunn S, Dinaj-Koci V, Li X, Stanton B. The influence of sensation-seeking and parental and peer influences in early adolescence on risk involvement through middle adolescence. Youth Soc 2013;48(2):220-41.

24. McKenna KY, Bargh JA. Plan 9 from cyberspace: The implications of the Internet for personality and social psychology. Personal Soc Psychol Rev 2000;4(1):57-75.

25. Chak K, Leung L. Shyness and locus of control as predictors of internet addiction and internet use. Cyberpsychol Behav 2004;7(5):559-70.

26. Yuen CN, Lavin MJ. Internet dependence in the collegiate population: The role of shyness. Cyberpsychol Behav 2004;7(4):379-83.

27. Lahey BB. Public health significance of neuroticism. Amer Psychol 2009;64(4):241-56.

28. Montag C, Jurkiewicz M, Reuter M. Low self-directedness is a better predictor for problematic internet use than high neuroticism. Comp Hum Behav 2010;26(6):1531-5.

29. Dong G, Wang J, Yang X, Zhou H. Risk personality traits of Internet addiction: A longitudinal study of Internet-addicted Chinese university students. Asia-Pacific Psychiatry 2012;5(4):316-21.

30. Adalier A, Balkan E. The relationship between internet addiction and psychological symptoms. Int J Global Educat 2012;1:42-9.

31. Gunduz HC, Eksioglu S, Tarhan S. Problematic internet usage: Personality traits, gender, age, and effect of dispositional hope level. Eurasian J Educ Res 2017;17(70):1-26.

32. Beck AT Thinking and depression: Theory and therapy. Arch Gen Psychiatry 1964;10:561-71.

33. Baloğlu M, Kozan HIÖ, Kesici Ş Gender differences in and the relationships between social anxiety and problematic internet use: Canonical analysis. J Med Internet Res 2018;20(1):1-9.

34. Dufour M, Brunelle N, Tremblay J, Leclerc D, Cousineau MM, Khazaal Y, Légaré AA, Rousseau M, Berbiche D. Gender difference in internet use and internet problems among Quebec high school students. Can J Psychiatry 2016;61(10):663-8.

35. Dufour M, Brunelle N, Khazaal Y, Tremblay J, Leclerc D, Cousineau MM, Rousseau M, Légaré AA, Berbiche D. Gender difference in online activities that determine problematic internet use. Journal de thérapie comportementale et cognitive 2017;27(3):90-8.

36. Lam LT, Peng ZW, Mai JC, Jing J. Factors Associated with Internet Addiction among Adolescents. Cyberpsychol Behav 2009;12(5):551-5.

37. Zuckerman M. Behavioral expressions and biosocial bases of sensation seeking. New York: Cambridge University Press; 1994.

38. Cross CP, Cyrenne DLM, Brown GR. Sex differences in sensation-seeking: A meta-analysis. Scientific Rep 2013;3(1):46-52.

39. Arnett, J. Sensation seeking: A new conceptualization and a new scale. Personal Individ Diff 1994;16(2): 28996.

40. Galloway G, Lopez K. Sensation Seeking and Attitudes to Aspects of National Parks: A Preliminary Empirical Investigation. Tourism Management 1999;20:665-71.

41. Zuckerman M, Neeb M. Demographic influences in sensation seeking and expressions of sensation seeking in religion, smoking and driving habits. Personal Individ Diff 1980;1(3):197-206.

42. Zuckerman M, Schultz DP, Hopkins TR. Sensation seeking and volunteering for sensory deprivation and hypnosis experiments. J Consult Psychol 1967;31(4):358-63.

43. Zuckerman M. Sensation seeking: Beyond the optimal level of arousal. Hillsdale, NJ: Lawrence Erlbaum Associates; 1979.

44. Jelenchick LA, Eickhoff J, Christakis DA, Brown RL, Zhang C, Benson M, Moreno MA. The Problematic and Risky Internet Use Screening Scale (PRIUSS) for adolescents and young adults: Scale development and refinement. Comp Hum Behav 2014;35:171-8.

45. Merlo LJ, Stone AM, Bibbey A. Measuring Problematic Mobile Phone Use: Development and Preliminary Psychometric Properties of the PUMP Scale. J Addiction 2013;1-7.

46. Campbell A. Staying alive: evolution, culture, and women's intrasexual aggression. Behav Brain Sci 1999; 22(2):203-14;

47. Sharma A, Sahu R, Kasar P, Sharma R. Internet addiction among professional courses students: A study from central India. Int J Med Sci Pub Health 2014;3(9):1069-73.

48. Morahan-Martin J, Schumacher P. Incidence and correlates of pathological Internet use among college students. Comp Hum Behav 2000;16:13-29. 
49. Mazhari S. The prevalence of problematic internet use and the related factors in medical students, Kerman, Iran. Addict Health. 2012;4(3-4):87-92.

50. Chaudhari B, Menon P, Saldanha D, Tewari A, Bhattacharya L. Internet addiction and its determinants among medical students. Industr Psychiatr J 2015;24(2):158-62.

51. Mihara S, Nakayama H, Osaki Y, Higuchi S. Report from Japan. Background paper prepared for the WHO Hong-Kong Meeting on Policy and Program Responses to Mental and Behavioral Disorders Associated with Excessive Use of the Internet and Other Communication and Gaming Platforms. Available through Department of Mental Health and Substance Abuse, World Health Organization, Geneva, Switzerland; 2016.

52. Leung L. Leisure boredom, sensation seeking, self-esteem, addiction symptoms and patterns of mobile phone use. In EA Konijn, S Utz, M Tanis and SB Barnes (Eds), Mediated Interpersonal Communication (pp.359381), NJ: Lawrence Erlbaum Associates; 2007.

53. Billieux J, Van der Linden M, Rochat L. The role of impulsivity in actual and problematic use of the mobile phone. Appl Cogn Psychol 2008;22:1195-210.

54. Pempek TA, Yermolayeva YA, Calvert SL. College students' social networking experiences on Facebook. J Appl Dev Psychol 2009;30:227-38.

55. Peele $\mathrm{S}$. The meaning of addiction. Lexington, MA: Lexington Books; 1985.

56. Saville BK, Gisbert A, Kopp J, Telesco C. Internet addiction and delay discounting in college students. The Psychological Record 2010;60(2):273-86.

57. Kreek MJ, Nielsen DA, Butelman ER, Laforge KS. Genetic influences on impulsivity, risk-taking, stress responsivity and vulnerability to drug abuse and addiction. Nat Neurosci 2005;8(11):1450-7.

58. Kish GB. A two factor theory of sensation seeking. Paper presented at the annual meeting of the American Psychological Association, Montreal; 1973.

59. Scalese M, Curzio O, Cutrupi V, Bastiani L, Gori M, Denoth F, Molinaro S. Links between psychotropic substance use and sensation seeking in a prevalence study: The role of some features of parenting style in a large sample of adolescents. J Addict 2014;1:1-14.

60. Zuckerman M. Sensation Seeking: Behavioral Expressions and Biosocial Bases. International Encyclopedia of the Social \& Behavioral Sciences 2015;5(3):607-14.

61. Priest S. The adventure experience paradigm. In Miles JC, Priest S. (Eds.), Adventure Programming (pp. 159162). State College, PA: Venture; 1999.

62. Lavin M, Marvin K, McLarney A, Nola V, Scott, L. Sensation seeking and collegiate vulnerability to Internet dependence. Cyberpsychol Behav 1999;2(5):425-30.

63. Ericsson Mobility Report. Data usage per smartphone is the highest in India- Ericsson. Retrieved from Ericsson: https://www.ericsson.com/en/press-releases/2/2019/6/data-usage-per-smartphone-is-the-highest-in-indiaericsson; 2019.

64. Puri R. Kantar's ICUBE report- Rural India propels India's Digital revolution; registers internet growth at $45 \%$. Retrieved September 07, 2020, from https://www.agencyreporter.com/kantar-icube-2020/; 6 May, 2020.

65. Kumar M, Mondal A. A study on Internet addiction and its relation to psychopathology and self-esteem among college students. Indian J Psychiatry 2018;27(1):61-6.

66. Billieux J. Problematic use of the mobile phone: a literature review and a pathways model. Curr Psychiatr Rev 2012;8:299-307.

67. Cha SS, Seo BK. Smartphone use and smartphone addiction in middle school students in Korea: Prevalence, social networking service, and game use. Health Psychology Open 2018;5(1):1-15.

68. Wu AM, Cheung VI, Ku L, Hung EP. Psychological risk factors of addiction to social networking sites among Chinese smartphone users. J Behav Addict 2013;2(3):160-6.

69. Kuss DJ, Griffiths M D, Binder JF. Internet addiction in students: Prevalence and risk factors. Comp Hum Behav 2013;29(3):959-66.

\footnotetext{
$* * * * * * * * * * * * * * * * * * * * * * * * * * * * * * * * * * * *$

Acknowledgements - Nil;

Conflict of Interest - Nil

Funding - Nil
} 